Biogeosciences Discuss., https://doi.org/10.5194/bg-2017-452

Manuscript under review for journal Biogeosciences

Discussion started: 13 November 2017

(c) Author(s) 2017. CC BY 4.0 License.

\title{
Lifestyle dependent occurrence of airborne fungi
}

Daniel A. Pickersgill ${ }^{1,2}$, Jörn Wehking ${ }^{1,2}$, Hauke Paulsen ${ }^{2}$, Eckhard Thines ${ }^{2}$, Ulrich Pöschl ${ }^{1}$, Janine Fröhlich-Nowoisky ${ }^{1}$, Viviane R Després ${ }^{1,2}$

${ }^{1}$ Max Planck Institute for Chemistry, Multiphase Chemistry Department, Hahn-Meitner-Weg 1, D-55128 Mainz, Germany

$5 \quad{ }^{2}$ Institute of Molecular Physiology, Johannes Gutenberg University, Johannes-von-Müller-Weg 6, D-55128 Mainz, Germany

Correspondence to: Daniel A. Pickersgill (d.pickersgill@mpic.de), Viviane R. Després (despres@uni-mainz.de) and Janine Fröhlich-Nowoisky (j.frohlich@mpic.de)

Abstract. Fungi play important roles in the environment, agriculture, and human health. Most fungal species spread by winddriven dispersal of spores, determining their occurrence and distribution in different environments. The dynamics of airborne

10 fungi and their dependence on lifestyle and environmental conditions, however, are not well characterized.

Here, we categorize the fungi detected in coarse and fine aerosol samples from continental boundary layer air using a lifestyle classification scheme that differentiates whether the fungi are (A) primarily associated to herbaceous or woody plants and (B), whether they are saprophytic, plant pathogenic, or surface inhabitants.

"Herbaceous" fungi exhibit stronger seasonal variations and correlations with meteorological factors. We find two distinct

15 clusters when viewing the distribution of the fungi between the coarse and fine size fractions. Pathogenic and surfaceinhabiting herbaceous fungi are shifted towards the coarse size fraction, adapted to impaction on plant surfaces, while saprophytic fungi are shifted towards the fine fraction or are evenly distributed, adapted more to sedimentation and longer atmospheric residence times.

"Wood" fungi display sporadic occurrences, seen for most saprophytes, or year-round occurrences with seasonal to polycyclic

20 peaks seen amongst pathogens. In comparison to herbaceous fungi they show weaker correlations with meteorological factors. They display more even coarse-fine distributions, which may be an adaptation to the calm conditions beneath the forest canopy. The differences reflect lifestyle-dependent sporulation strategies which may facilitate and improve the assessment and forecasting of the abundance and spread of pathogenic fungi and related issues such as crop protection in view of land-use and climate change.

\section{1. Introduction}

Amongst the primary bioaerosol particles (PBAP) (Després et al., 2012) of the atmosphere, fungal spores are one of the most important groups. Typical number concentrations range from $\sim 10^{3}-10^{4}$ per cubic meter of air (Elbert et al., 2007; FröhlichNowoisky et al., 2012), in the same orders of magnitude as bacteria, albeit with large variations depending on location, time of year, or even time of day. Fungal spores show a large species-dependent variability in size, with aerodynamic diameters

30 ranging from $\sim 1$ to $50 \mu \mathrm{m}$. Most species, however, have spores in a size range of roughly 2 to $10 \mu \mathrm{m}$ aerodynamic diameter (Cao et al., 2014; Després et al., 2012; Elbert et al., 2007; Fröhlich-Nowoisky et al., 2009; Huffman et al., 2010; Wang et al., 
Biogeosciences Discuss., https://doi.org/10.5194/bg-2017-452

Manuscript under review for journal Biogeosciences

Discussion started: 13 November 2017

(c) Author(s) 2017. CC BY 4.0 License.

2008). As plant pathogens Fungi have a huge impact on agriculture and forestry (Ostry and Juzwik, 2008; Strange and Scott, 2005; Zabel and Morrell, 2012) and as pathogens and allergens on human health (Horner et al., 1995). Their influence on atmospheric processes is also subject of ongoing discussions, as individual species have displayed ice-nucleating abilities far more efficient than non-biological aerosols, and, thus, they may influence cloud formation (Fröhlich-Nowoisky et al., 2015,

5 2016; Pöschl, 2005; Richard et al., 1996).

So far, most studies dealing with temporal dynamics of the atmospheric microbiome take the viable approach of focusing on the taxonomic relations within the community as the foundation of analysis (Bowers et al., 2012, 2013; Franzetti et al., 2011; Fröhlich-Nowoisky et al., 2009, 2012, 2014; Yooseph et al., 2013). However, as frequently found in nature, an organism's characteristics are strongly shaped by the ecological niche, i.e., lifestyle, the organism is adapted to. Some aspects may show

10 a higher similarity to distant relatives adapted to a similar lifestyle, rather than to close relatives adapted to an entirely different niche. This means that viewing PBAP solely from a taxonomic perspective, especially at high taxonomic ranks, could hinder the identification of important characteristics and patterns, as closely related species may be displaying substantial differences. Although wind-driven dispersal is a passive process, through evolutionary adaptation to their lifestyle, fungi can heighten their inoculation probability, i.e., success rate of a spore forming a new colony. These adaptations can be variations in numerous properties and will include aspects like the numbers of released spores, aerodynamic properties of spores (such as size, shape, density, and surface composition), and especially the time of spore release, which we will cumulatively refer to as the "sporulation strategy". The evolutionary pressures leading to differing sporulation strategies will be factors, such as the spatial distribution and abundancy of a nutrient source e.g., if a fungus is a pathogen or a decomposer of dead plant material both will require entirely different sporulation strategies. In addition, the habitat of a fungal species should play a large role. On a global

20 scale, latitude and therefore the seasonal climatic and vegetative cycle will influence the presence of a nutrient source, requiring a seasonal release of spores. On a regional to local scale the habitat and its microclimatic conditions, e.g., a sheltered forest atmosphere in comparison to open grasslands, will require differing strategies. Furthermore, meteorological factors are known to influence the fungal life cycle, from hyphal growth (Donnelly and Boddy, 1997; Dowson et al., 1989; van Laarhoven et al., 2015) up to spore formation and liberation (Elbert et al., 2007; Jones and Harrison, 2004), and will therefore ultimately also

25 be major governing factors in the sporulation strategy. Moreover, insight into the influence of meteorological factors on sporulation is of critical importance to understand and estimate the impacts of climate change, which is especially important for agriculture, due to the high abundance of fungal plant pathogens. The identification of occurrence and abundancy patterns and the main environmental factors influencing them are of key importance when it comes to developing forecast models or even large scale global models, especially in view of the changing conditions in the Anthropocene.

30 In this study, we take the novel approach and introduce a simple lifestyle classification system to the abundant species and genera identified in a previous study by Fröhlich-Nowoisky et al., 2009, "High diversity of fungi in air particulate matter". This allows the identification of common patterns found amongst taxa adapted to similar lifestyles. 
Biogeosciences Discuss., https://doi.org/10.5194/bg-2017-452

Manuscript under review for journal Biogeosciences

Discussion started: 13 November 2017

(c) Author(s) 2017. CC BY 4.0 License.

\section{Material and methods}

This study is based on the data obtained from a study by Fröhlich-Nowoisky et al.,2009. The following description is to be regarded as a short overview. For a detailed description of the applied laboratory methods please refer to the original publication.

\section{2.1. Aerosol sampling}

Sampling was conducted with a high-volume dichotomous sampler [self-built based on Solomon et al., "High-Volume Dichotomous Virtual Impactor for the Fractionation and Collection of Particles According to Aerodynamic Size" (Solomon et al., 1983)] using sterilized glass fiber filters (PALL Corporation, Type A/A, 102-mm, sterilized at $500{ }^{\circ} \mathrm{C}$ for $12 \mathrm{~h}$ ). The sampler was operated with a rotary vane pump (Becker VT.25) with a flow rate of $300 \mathrm{~L} \mathrm{~min}^{-1}$, which corresponds to a cut-

10 off of approx. $3 \mu \mathrm{m}$ aerodynamic diameter, separating the aerosols in the air sample onto separate coarse and fine particulate matter filters. The coarse particles $(>3 \mu \mathrm{m}$ ) were collected through a virtual impactor, in line with the inlet, with a flow rate $30 \mathrm{~L} \mathrm{~min}^{-1}$ while the fine particles $(<3 \mu \mathrm{m})$ were collected perpendicular to the inlet, with a flow rate of $270 \mathrm{~L} \mathrm{~min}^{-1}$. Furthermore, it should be mentioned that an estimated $10 \%$ of fine particulate matter, due to sampler design, is collected in the coarse fraction (Solomon et al., 1983).

15 The sampling site was in Mainz (130 m a.s.l), Germany, on the roof of the old 3-storey Max Planck Institute for Chemistry building on the campus of the Johannes Gutenberg University (49 $\left.59^{\prime} 31.36^{\prime \prime} \mathrm{N}, 8^{\circ} 14^{\prime} 15.22^{\prime \prime} \mathrm{E}\right)$. The sampler was attached to a mast approximately $5 \mathrm{~m}$ in height above the roof top. The surroundings in the direct vicinity of the sampling location are predominately urban to the north and east, whilst strongly dominated by agriculture to the south and west. The first small forests, approximately $2-5 \mathrm{~km}^{2}$ in size, can be found approximately $3.5-5 \mathrm{~km}$ in distance to the north-west and south west. The first large forests, of over $100 \mathrm{~km}^{2}$ can be found to the north and east at a range of $10-15 \mathrm{~km}$.

The samples were collected over a 13-month period (March 2006-April 2007). The individual sampling durations were generally seven days, corresponding to an air volume of approximately $3000 \mathrm{~m}^{3}$, with a few exceptions which had durations of 1-5 days $\left(\sim 400-2000 \mathrm{~m}^{3}\right)$. Altogether 42 sets of coarse and fine particulate filters were analyzed, which amount to a combined sampling time of $\sim 37$ weeks in the 13-month period. Information concerning the individual samples can be seen in table S1 in the supporting information of Fröhlich-Nowoisky et al., 2009. To rule out contaminations during the sampling procedure, additional controls were performed. Blank samples comprised filters that were not used for sampling but only sterilized and extracted alongside the actual samples ("extraction blanks") to monitor the quality of the DNA extraction process. Two sets of filters were used to control the sampling procedure, where one filter set was mounted in the sampler and the pump turned on for $5 \mathrm{~s}$ ("start-up blanks") and the other filter sample set was equally mounted in the sampler but the pump

30 was not turned on ("mounting blanks"). The sampling blanks were collected at regular intervals ( 4 weeks) after a thorough cleaning of the sampler, and extraction blanks were included in each extraction process. None of the tested blanks contained detectable DNA. 
Biogeosciences Discuss., https://doi.org/10.5194/bg-2017-452

Manuscript under review for journal Biogeosciences

Discussion started: 13 November 2017

(c) Author(s) 2017. CC BY 4.0 License.

\subsection{DNA extraction and sequence analysis}

Total DNA was extracted from filter aliquots (1/8-1/4) using a commercial soil extraction kit (LysingMatrixE, FastDNASpin Kit for Soil, MP Biomedicals). The extracted DNA was amplified via PCR with multiple primer pairs that target the ITS15.8S-ITS2 and 18S regions of the rRNA region (see Fröhlich-Nowoisky et al., 2009). The amplification products were cloned

5 using the TOPO TA Cloning Kit (Invitrogen) and $~ 12$ to 24 colonies were randomly selected for further analysis, based on blue-white selection. A PCR was then performed on the selected colonies, using the vector specific primers M13F-40 and M13R (Sigma-Aldrich). To monitor possible contaminations, PCR blanks were included in all runs. The isolated cloned fragments were then further processed by a restriction fragment length polymorphism (RFLP) analysis to avoid unnecessarily sequencing of identical sequences. The Max Planck-Genome-centre Cologne, Germany (http://mpgc.mpipz.mpg.de/home/)

10 performed the sequencing of the selected amplification products. In total 1513 sequences were determined, of which 17 were removed due to chimeric results, resulting in 1496 sequences. The sequences were then grouped into 368 operational taxonomic units (OTUs) based on a 97\% sequence identity (OTU reference sequences accession numbers: FJ820489-FJ820856). Here, an OTU represents a (hypothetical) fungal species, as the intra-species variation of the ITS regions is usually below $3 \%$ (O'Brien et al., 2005). The taxonomic affiliation of the OTUs was assessed using a BLAST search of the NCBI, whereby the

15 OTUs were allocated to the lowest possible taxonomic level.

\subsection{Dataset, subsets, and lifestyle classification}

Dependent on the performed analysis either the entire OTU dataset from Fröhlich-Nowoisky et al., 2009, were used or, where more statistically robust data were needed, sub-datasets were queried, comprised of OTUs identified to species or genus level found in at least three samples (3-sample-subset) or in five samples (5-sample-subset). The three and five sample cut-offs were chosen as three samples are the minimum needed when searching for linear tendencies and five samples constitute approximately $10 \%$ of all samples. The 3-sample-subset comprises 73 of the original 368 OTUs, which fall into 51 distinct taxa, while the 5-sample-subset contains 39 OTUs from 26 taxa. However, in the case of taxa comprised of multiple OTUs identified to genus level, the ending spp. was added. Furthermore, two Aspergillus OTUs (Aspergillus sp.(A.) and Aspergillus sp.(B)) were not combined to a single taxon, firstly due to the importance of Aspergillus and secondly as both OTUs displayed distinct differences in the size fraction distribution, leading us to believe them to be separate species. A list containing the taxa included in the subsets can be found in the supplementary table S1.

The low taxonomic ranks within the subsets allowed additional information on the taxa to be gathered from literature. Based on our findings a simple 2-step classification scheme was introduced to describe the predominant lifestyles of the identified fungi. It was found that all taxa, for varying reasons, could be associated either to herbaceous or woody plants. Therefore, as

30 a first step, they were classified as "herbaceous" or "woody" fungi. In a second step, the taxa were grouped dependent on whether they were A. saprophytic, i.e., decomposers of dead material, or B. plant pathogens, or C. merely known as surface inhabitants of herbaceous plants or trees. Combinations of the second-degree classifications were used to allocate ambiguous 
Biogeosciences Discuss., https://doi.org/10.5194/bg-2017-452

Manuscript under review for journal Biogeosciences

Discussion started: 13 November 2017

(c) Author(s) 2017. CC BY 4.0 License.

genera or species, such as species known to be facultative pathogens or genera known to contain pathogens and saprophytes. The allocation of the subset taxa can also be seen in the supplementary table S1.

\subsection{Statistical analysis}

The data presented in Fröhlich-Nowoisky et al., 2009, was imported into a self-designed MySQL based database system

5 (MySQL Community Server Version 5.6.29) along with meteorological data from a weather station in Mainz-Mombach, provided by the ZIMEN Luft Messnetz of the Landesamt für Umwelt Wasserwirtschaft und Gewerbeaufsicht. The meteorological data contain $1 / 2 \mathrm{~h}$ values for temperature, relative humidity, and precipitation and $1 \mathrm{~h}$ values for wind speed and direction for the entire 13-month sampling duration. For a unified taxonomic affiliation, the taxonomy from the catalogue of life (Roskov et al., 2015) was used. Furthermore, literature data, such as the spore sizes and lifestyle classification seen in

10 Table S1 for the subsets were integrated into the database.

All calculations were performed either by direct database queries or, for more complex operations, using the script languages Python (Version 2.7) or R Statistics (Version 3.1.0).

To compare the OTU composition between different air samples ( $\beta$-diversity) the Bray Curtis Dissimilarity Index $\left(B C_{i j}\right)$ was calculated between all samples.

$15 B C_{i j}=1-\frac{2 C_{i j}}{S_{i}+S_{j}}$

Here, $C_{i j}$ are the number of OTUs sample $i$ and $j$ have in common. $S$ is the number of total OTUs (species richness) found on sample $i$ or $j$.

For each taxon in the 5-sample-subset we calculated coarse-fine ratio $(\bar{S})$

$\bar{S}=\frac{s_{c}-s_{f}}{s_{\text {tot }}}$

20 Here, $S_{\text {tot }}$ is the total number of samples a taxon was found in, while $S_{c}$ and $S_{f}$ are the number of coarse or fine fraction occurrences, respectively. $\bar{S}$ can therefore vary between +1 and -1 . A value of +1 indicates that a taxon was exclusively found in the coarse fraction, while -1 indicates occurrences exclusive to the fine fraction. A value of zero shows an even distribution between the size fractions. In Figure 4 the scale was replaced with fine (-1), even $(0)$ and coarse $(+1)$.

To compare $\bar{S}$ to the taxon-specific spore sizes, we calculated a shape-corrected theoretical aerodynamic diameter $\left(\mathrm{d}_{\mathrm{a}}\right)$ for each

25 species and genus in the 5-sample-subset. The aerodynamic diameter of a particle is defined as the diameter of a spherical particle with a density of $1 \mathrm{~g} \mathrm{~cm}^{-2}$ with the same aerodynamic properties or settling velocity as the particle. In a first step the spore dimensions and shape were retrieved from literature and can be found in the supplementary material, table S1. Fungal species belonging to the phylum Ascomycota are known to produce both asexual spores, known as conidia, which some species exclusively produce, and sexual spores generally referred to as Ascospores. For a uniform approach in cases where species

30 produce both spore types we used the dimensions of the conidia, as these usually outweigh the sexual spores in some species, e.g., for Aspergillus nidulans (Tsitsigiannis et al., 2004). Furthermore, it is said, for many Ascomycota, sexual stages can be hard to find in nature (Taylor et al., 1999). To simplify calculations, non-spherical spores were treated as ellipsoids, which was 
Biogeosciences Discuss., https://doi.org/10.5194/bg-2017-452

Manuscript under review for journal Biogeosciences

Discussion started: 13 November 2017

(c) Author(s) 2017. CC BY 4.0 License.

true in most cases. Using the lengths (l) and widths $(w)$ of the non-spherical spores the volumetric equivalent diameter ( $\left.\mathrm{d}_{\mathrm{vol}}\right)$ was calculated with the following ellipsoid volume equation:

$d_{v o l}=\left(w^{2} \times l\right)^{\frac{1}{3}}$

Using the length to width ratio $(\mathrm{q})$ the dynamic shape correction factor $(\kappa)$ was calculated assuming the spore polar axis is

orientated horizontal to the airflow with the following equation (Davis and Schweiger, 2002).

$\kappa=\frac{8}{3} \frac{q^{-1 / 3}}{\left\{\frac{q}{\left(q^{2}-1\right)}+\frac{1}{\sqrt{q^{2}-1}}\left[1-\frac{1}{2\left(q^{2}-1\right)}\right] \ln \left(\frac{q+\sqrt{q^{2}-1}}{q-\sqrt{q^{2}-1}}\right)\right\}}$

A horizontal orientation should be true for settling spores of homologous density in still air, as the horizontal orientation maximizes air resistance.

Using $d_{v o l}$ and $\kappa$ the theoretical aerodynamic diameter $\left(d_{a}\right)$ of the elliptical spores could then be calculated:

$10 d_{a}=\sqrt{\frac{\rho_{\text {spore }}}{\rho_{0} \kappa}} d_{v o l}$

With $\rho_{0}$ being the unit density $\left(1 \mathrm{~g} \mathrm{~cm}^{-2}\right)$ and $\rho_{\text {spore }}$ being the spore density. As the species and genus spore densities could not be found in literature and are known to vary between species, a density of $1 \mathrm{~g} \mathrm{~cm}^{-2}$ was uniformly used. Therefore, for spherical spores $d_{a}=d_{v o l}=d$ and for non-spherical spores $d_{a}=(1 / \kappa)^{1 / 2} d_{v o l}$.

For relative frequency of occurrence timelines $(\mathrm{RFO}=$ Number of samples a taxon was found on / the total number of analyzed

15 samples, in a time frame), seen in Figure 4, and meteorological correlations, seen in Figure S2, the 3-sample-subset was used. For higher statistical validity, the samples were grouped into months, with samples on the border of two months allocated to the month which was sampled longest. For each identified species or genus various monthly occurrence parameters were calculated, including the RFO values. Furthermore, meteorological data within the individual sampling periods were also pooled into months. The monthly sampling period averages, standard deviation, maximum and minimum values for

20 temperature, humidity, and wind speed were calculated. For precipitation, the sum precipitation was calculated, along with an approximation of the duration of precipitation by summing every half hour with a precipitation larger than 0 mm and approximated precipitation strength (sum of precipitation / approximated duration).

To assess whether there are increasing or decreasing tendencies between taxa RFOs and the above-mentioned meteorological parameters, the Spearman's Rank coefficients were calculated, along with p-values which describe the probability of random

25 variables producing the observed correlation. All abbreviations and formulae are detailed in the supplementary table S2.

\section{Results and discussion}

From the 42 analyzed air samples, comprising coarse and fine fraction particulate filters, which were collected between March 2006 and April 2007 in Mainz, Germany, 368 OTUs, from 1496 obtained DNA sequences, were identified and discussed in Fröhlich-Nowoisky et al., 2009.The isolated DNA can stem both from fungal spores and hyphal fragments emitted into the 
Biogeosciences Discuss., https://doi.org/10.5194/bg-2017-452

Manuscript under review for journal Biogeosciences

Discussion started: 13 November 2017

(c) Author(s) 2017. CC BY 4.0 License.

atmosphere. Hyphal fragments, however, have been found to be roughly, at least, an order of magnitude lower in number concentration than spores $\left(\sim 10^{2} \mathrm{~m}^{-3}\right)$ (Pady and Gregory, 1963). We therefore assume the sequences to stem primarily from spores, which is also strengthened by observations and discussed in detail below.

The 97\% identity of sequences within an OTU roughly accounts for the inner species variability of the analyzed rDNA ITS

5 region, thus, an OTU can be seen as a hypothetical species (O'Brien et al., 2005). The post-editing representative OTU sequences (NCBI Acc.: FJ820489-FJ820856), so the sequences chosen to represent an OTU sequence cluster, were on average 630 base pairs in length. The relatively long reference sequences allowed Fröhlich-Nowoisky et al., 2009, to identify the OTUs down to low taxonomic ranks. Out of the 368 OTUs, approximately $30 \%$ could be identified down to species level and $25 \%$ to genus level. The remaining $45 \%$ OTUs were identified to the rank of family or higher. It was found that $64 \%$ of the

10 identified OTUs belonged to the phylum Basidiomycota (BMC) while 34\% were allocated to the Ascomycota (AMC). The remaining $2 \%$ were identified as Fungi incertae sedis (FIS), so of uncertain taxonomic placement.

In Figure 1a we view the occurrence-weighted taxonomic composition, i.e., weighted by the number of sample occurrences giving more weight to the abundant taxa, within the entire dataset and the 3- and 5-sample-subsets. A comparison to an unweighted version taxonomic composition, i.e., species richness, can be seen in the supplementary material (Figure S1). As

15 can be seen in Figure 1a the TSP (total suspended particles) phylum-level distribution of the entire dataset the 60:40 BMC to AMC ratio described by Fröhlich-Nowoisky et al., 2009, is still observed (Fig. 1a entire dataset $~ 62: 38$ ). Furthermore, even though the two subsets comprise only $\sim 20 \%$ and $\sim 11 \%$ of the original OTUs, the BMC to AMC ratio of roughly $60: 40$ is basically also seen (3-sample-subset: 59:41, 5-sample-subset: $\sim 54: 46$ ), with an increase of $8 \%$ in the proportion of AMC amongst the more abundant taxa. Furthermore, the phylum distribution shown for the coarse and fine fractions of the 3-sample-

20 subset are near identical, differing only by tenths of a percentile. This shows that the BMC to AMC ratio is also constant for fungal spores larger and smaller than $\sim 3 \mu \mathrm{m}$ aerodynamic diameter, which is interesting as the extensive study of Yamamoto et al (33) observed a strong size dependency in the AMC to BMC ratio, with BMC dominating in smaller size fractions and AMC dominating in the larger size fractions (Yamamoto et al., 2012). This seeming contradiction is discussed in more detail below.

25 The composition on family-level in the 3-sample-subset, however, exhibits distinct differences between the coarse and fine particle fraction. In most cases, families can be found in both the coarse and fine particle fractions, except for the Erysiphaceae (Blumeria graminis) which were found exclusively in the coarse particle fraction (3.3\%) and the Cordycipitaceae and Wallemiaceae both only detected in the fine particle fraction (both cases $\sim 1 \%$ ). However, substantial proportional differences are often observed for families found in both fractions. Amongst the BMC the blastoconidia (i.e., actively discharged spores)

30 forming yeast-like Cystofilobasidiaceae make up $6.3 \%$ of the occurrences in the coarse particle fraction and only $0.8 \%$ within the fine particle fraction. Amongst the AMC, the family of mold-like Trichocomaceae, to which the cosmopolitan genera Aspergillus and Penicillium belong, make up $15.1 \%$ of the fine fraction taxon occurrences while only $3.7 \%$ of the coarse fraction. In contrast, a second AMC family of mold-like fungi, the Pleosporaceae, containing the genera Epicoccum and 
Biogeosciences Discuss., https://doi.org/10.5194/bg-2017-452

Manuscript under review for journal Biogeosciences

Discussion started: 13 November 2017

(c) Author(s) 2017. CC BY 4.0 License.

Alternaria and known to include many plant pathogenic species, are predominately found in the coarse fraction, making up $11.3 \%$, while only $1.2 \%$ of the fine fraction.

The most abundant class found, the Agaricomycetes, which for reasons of clarity were not resolved down to family level in Figure 1, are slightly increased in the fine fraction making up $54.4 \%$ of the occurrences while they make up $47.2 \%$ in the coarse fraction. In comparison to the other classes found in the study, this class is highly diverse on family level made up of 19 families (and Phlebiella sp. which is not assigned to a family in the Catalogue of Life (Catalogue of Life: 2016 Annual Checklist; http://www.catalogueoflife.org/)), more than all other classes combined. However, individually most of the families only make up small proportions, with only 3 families having TSP occurrences higher than 5\% (Meruliaceae 11.4\%, Polyporaceae $6.8 \%$ and Bondarzewiaceae $6.4 \%$ ).

10 Applying the lifestyle classifications scheme to the 51 taxa in the 3-sample-subset, 30 taxa (59\%) were associated with dead wood or trees, so they predominantly either live as wood decomposers, tree parasites, or are found on the surface of trees. The remaining 21 taxa (41\%) were associated to herbaceous material or non-woody plants, again being decomposers, parasites, or surface inhabitants. The affiliation of each taxon can be seen in supplementary table S1. Of course, many fungi can survive on a vast array of different hosts and substrates, can be opportunistic pathogens or display complex life cycles, making an exact

15 categorization challenging especially on genus level. The used classification scheme was kept as simple as possible and therefore should be seen as a rough grouping scheme developed to be sufficient for the analysis performed in this study.

Figure $1 \mathrm{~b}$ shows the occurrence-weighted lifestyle classification composition of the 3-sample-subset (for an unweighted version see supplementary Figure S1), along with the phylum level distribution for each group (sidebars). In TSP, 48\% of all occurrences are of herbaceous-plant-associated fungi while $\sim 52 \%$ are of woody-plant-associated fungi. Furthermore, the

20 distribution on phylum level shows that the herbaceous-plant-associated fungi are dominated by AMC (83.6\%) whilst only $16.4 \%$ are BMC, which are all parasitic or leaf surface inhabiting yeast-like fungi. In contrast, the woody-plant-associated fungi are almost exclusively BMC (with the exception of Cistella acuum, an AMC known to grow on pine needles) which, as can be seen in Fig. 1a, are mainly Agaricomycetes. The detected Agaricomycetes taxa are mostly saprophytic but also include some economically important plant pathogenic species, such as Heterobasidion annosum, which is abundant in air and responsible for an estimated 800 million Euros of damages per year in Europe (Stenlid et al., 2000).

When viewing the classification composition for the coarse and fine fractions separately, 52\% of taxon occurrences in the coarse fraction are herbaceous-plant-associated, while they make up only $\sim 42 \%$ in the fine fraction. This is mainly due to a higher proportion of plant pathogens in the coarse fraction, as also described in Fröhlich-Nowoisky et al., 2009,. In the coarse fraction plant pathogens comprise $18.3 \%$ (up to $46.5 \%$ when including taxa identified to be potential pathogens), compared to

$305.8 \%$ (up to $35.1 \%$ ) in the fine fraction. A larger aerodynamic diameter and therefore higher inertia will increase the impaction efficiency of a spore by reducing the tendency to follow the airflow around the plant surface (Deacon, 2013; Gregory, 1961). There are a high proportion of woody-plant-associated fungi ( 52\% in TSP) observed in the entire dataset and subsets. However, the area around the sampling site is shaped more by urban and agricultural areas, interspersed with trees, rather than larger forested areas. In the direct vicinity of the sampling location, urban areas dominate to the north and east, whilst 
Biogeosciences Discuss., https://doi.org/10.5194/bg-2017-452

Manuscript under review for journal Biogeosciences

Discussion started: 13 November 2017

(c) Author(s) 2017. CC BY 4.0 License.

agriculture strongly dominates the south and west. The first small forests (approximately $2-5 \mathrm{~km}^{2}$ in size) can be found approximately $3.5-5 \mathrm{~km}$ to the north-west and south west, while the first large continuous forested areas $\left(>100 \mathrm{~km}^{2}\right)$ can be found to the north and east in a range of 10-15 km. While these ranges are by no means outside the theoretical distances that can be travelled by spores in the atmosphere, and furthermore the urban and agricultural areas aren't void of trees, one could still expect the herbaceous-plant-associated fungi to outweigh woody-plant-associated fungi. The observed taxa within this study, however, draw a different picture. Not only is the proportion of woody-plant-associated taxa slightly higher than the herbaceous-plant-associated taxa, but also from the perspective of individual taxa as some of the tree pathogenic taxa are amongst the most abundant observed in the study. This may be an indication either that forests are a significant emission source of fungal spores in fragmented and anthropogenically shaped landscapes, typical to northern continental Europe or that even

10 relatively low numbers of trees in an area can have significant influence on the atmospheric spore composition. Also, the higher relative proportion in the fine fraction ( $57 \%$ compared to $48 \%$ in the coarse fraction) may help to explain the high proportions, as small spores could have a longer atmospheric residence time, and therefore higher accumulation rates in the atmosphere.

Figure 2 shows the TSP, i.e., combined coarse and fine fraction, inter-sample variability in composition ( $\beta$-diversity) of the

15 entire dataset using the Bray-Curtis-Index. In general, air samples in close temporal vicinity (near the diagonal) display a higher similarity when compared to samples taken half a year later or earlier. This shows a clear seasonality in the composition of atmospheric fungi. However, the short-term sample-to-sample variability in OTU composition is not constant throughout the 13-month period. On the one hand the plot regions A and C, corresponding to spring until late summer 2006 and winter 2006 to spring 2007, display long periods of relatively high sample-to-sample similarity $(<0.75)$, with winter 2006 showing

20 the highest consistency compared to the other seasons. On the other hand, the plot region B, corresponding to late summer and autumn of 2006, displays a low sample-to-sample consistency (predominately >0.75), which indicates a period of high diversity and dynamic variability in the atmospheric fungal composition. These findings coincide with the findings in FröhlichNowoisky et al., 2009, which showed the absolute fungal species richness $\left(\mathrm{S}_{\mathrm{n}}\right)$ when grouped into meteorological seasons was highest in autumn and lowest in winter, while spring is slightly more diverse than summer.

25 Interestingly the end of winter 2006/07 (plot region D) displays high similarities to the samples taken in spring and even summer of 2006. The analyzed time period in Germany was rather unique from a climatic perspective. According to the DWD (Deutscher Wetter Dienst), winter 2005/06 was the coldest in over a decade with an average temperature of $-0.7^{\circ} \mathrm{C}$ while the winter of 2006/07 was, up to that time, the warmest in recorded history with an average temperature of $+4.4^{\circ} \mathrm{C}$ (decadal winter time average $2001-10:+1.1^{\circ} \mathrm{C}$ ). The unusually warm winter, in our opinion, is the most feasible explanation for the observed

30 high similarities, which may have led to a much earlier sporulation onset. These results are rather astounding with, e.g., the winter sample MZ 90 showing identities to summer samples comparable to the sample-to-sample identities within the summer season itself. This might be an indication of the far-reaching influence that a changing climate will have. An earlier onset of sporulation might benefit the spread and growth of fungal pathogens, prolong sporulation periods and allow for additional sporulation events for species with multiple generations per year. These in turn could have unforeseeable effects on, e.g., 
Biogeosciences Discuss., https://doi.org/10.5194/bg-2017-452

Manuscript under review for journal Biogeosciences

Discussion started: 13 November 2017

(c) Author(s) 2017. CC BY 4.0 License.

agriculture, local flora and fauna, or the allergic sensitization and exposure towards fungal species (Boddy et al., 2014; Fröhlich-Nowoisky et al., 2016; Gange et al., 2007; Wolf et al., 2010).

The RFO (relative frequency of occurrence) timelines seen in Figure 3 give a more detailed insight into the earlier sporulation observed in Figure 2. If one assumes little or no bias throughout the laboratory procedures, a high RFO value should

5 approximate a high proportion amongst the atmospheric spore population of a month. A low RFO value, on the other hand could reflect either a low proportion or even a temporally highly confined release of spores within a fraction of the analyzed sampling periods of a month. Boddy et al. (Boddy et al., 2014) investigated the influence of climate change on the development of the fruiting bodies of Basidiomycetes in Europe and reported an on average, 18-day earlier onset of springtime fruiting fungi in the United Kingdom and Norway, which in both countries was correlated with high winter temperatures (Boddy et al.,

10 2014). Our results agree with their findings and point to a similar influence on Ascomycetes. April and May of 2006 display a high diversity with nearly all taxa showing an atmospheric presence within the two-month period. A very similar occurrence pattern can again be seen in January and February of 2007, which points to an up to three-month-earlier onset of spore release. Furthermore, the sporulation shift is especially obvious amongst pathogens and potential pathogens of both woody and herbaceous plants. Due to the vast potential influences, there is a dire need to study further and forecast the potentially diverse

15 effects of a changing climate, such as rising temperatures or changing precipitation patterns, on the sporulation of fungi to develop combative strategies to limit harm to be expected.

When comparing the lifestyle classifications in Figure 3, distinct patterns can be observed in the timelines. In general, the herbaceous-plant-associated fungi as a whole are more frequent, found on average in approx. 11 of the 42 samples, while woody-plant-associated fungi are found on average in approx. 8 samples. However, as mentioned above, the woody-plant-

20 associated fungi are more diverse, comprising 31 taxa compared to the herbaceous-plant-associated fungi comprising only 20 taxa.

The timelines of the herbaceous-plant-associated fungi in most cases show seasonality with one to two annual peaks that correspond to different stages in the annual life cycle of plants. The two genera Alternaria and Epicoccum, to which many plant pathogenic mold species belong, display 6 to 7 month continuous occurrences and summertime peaks, with Epicoccum displaying an earlier sporulation onset. This corresponds to the developing and fully developed vegetative stages of most plants in northern Europe. This may indicate that the sampled taxa are in fact pathogenic or at least inhabit the surfaces of plants. Botryotinia fuckeliana (anamorph: Botrytis cinerea) a pathogenic fungus with a very broad host range, mostly known to infect fruits, shows a high RFO value in April 2006. This most probably corresponds to an initial sporulation after winter dormancy, after which there is a decrease in May and steady increase up to a maximum September to November, which corresponds to

30 the months where host fruits, such as grapes and apples, are ripe.

The two mold genera Cladosporium and Penicillium allocated to the herbaceous plant fungi, on the other hand, show a yearround presence. Cladosporium sp. is found in all but one sample, indicating a year-round high abundance. Penicillium spp. were found in all but one month with mostly mid to low RFO values but reaches $100 \%$ for the final three months of sampling. 
Biogeosciences Discuss., https://doi.org/10.5194/bg-2017-452

Manuscript under review for journal Biogeosciences

Discussion started: 13 November 2017

(c) Author(s) 2017. CC BY 4.0 License.

The continuous presence of the mold genera perhaps also reflects the unspecific nature of their sporulation strategies, which can be adopted due to the ubiquity of potential substrate in the environment.

In contrast to the herbaceous-plant-associated fungi, the woody-plant-associated fungi show entirely different occurrence patterns. The saprophytic taxa, apart from Phlebia sp., mainly show sporadic occurrences and low RFO values, this might reflect the relatively large distance to forested areas (approx. $3.5 \mathrm{~km}$ ) or even a shielding effect of the forest canopy reducing spore emissions into the free atmosphere. However, the taxa identified as tree pathogens or potential pathogens show completely different occurrence patterns compared to the wood saprophytes. Most of the taxa are amongst the most abundant identified within the study showing a year-round presence with frequently high RFO values. If forests are presumed to be the primary emission sources for all woody-plant-associated fungi, it leads to the question why do the occurrences differ in such

10 a way? They may simply reflect the height of emission above the ground. The saprophytic fungi will mainly release their spores from fruiting bodies at the forest floor, while pathogenic fungi or fungi colonizing trees and dead attached branches will generally release their spores from a greater altitude into turbulent airflow below. Furthermore, it is possible that tree pathogenic fungi produce significantly more spores over long periods of time compared to wood saprophytes. Many tree pathogens are known to form long-term fruiting bodies e.g., for Bjerkandera adusta which produces fruiting bodies year round

15 (Kuo, 2010). Such a sporulation strategy will heighten the infection probability in cases where, for example, a wounded or weakened host is needed, while saprophytes can generally rely on having dead wood in close vicinity to their emission source. Another explanation would be a different emission source for pathogens, closer to the sampling site. Trees in urban areas may be infected by pathogens, while dead decomposing wood is mostly removed in urban areas and therefore saprophytic fungi generally might be less abundant. Furthermore, trees in urban areas may be more susceptible to pathogens due to pollution.

20 As mentioned above, most of the pathogenic and potentially pathogenic woody-plant-associated fungi exhibit a year-round presence. Some of the taxa also show a clear seasonality, such as Bjerkandera spp. and Trametes spp. that both show peaking RFO values early in both years. Some taxa also exhibit summertime peaks such as Peniophora spp. and Bjerkandera spp. Other taxa, such as Vuilleminia comedens and Stereum spp., exhibit relatively stable year-round RFO values. Heterobasidion annosum perhaps has the most interesting occurrence pattern of all depicted taxa, which shows an annually polycyclic occurrence, i.e., after a peaking value the RFO value gradually decreases over a two to three-month period after which there is another peak, independent from the seasons.

So, similar to mold fungi, which release vast quantities of spores more or less independent of the season, the wood pathogens and potential pathogens seem to adopt a similar strategy, although in contrast, perhaps not due to the ubiquity of substrate in the environment but rather due to its scarcity and therefore low inoculation success rate.

30 To investigate a possible influence of climatic factors on the atmospheric presence of the taxa, Spearman's rank correlation coefficients were calculated between the RFO values and the meteorological factors. The detailed results can be seen in the supplementary material (SI Influence of meteorology, Figures S2 and S3.

On a whole the strongest correlations are observed with temperature and wind speed. On the other hand only a few significant correlations are observed with relative humidity and precipitation, both known to be important factors for short-term spore 
Biogeosciences Discuss., https://doi.org/10.5194/bg-2017-452

Manuscript under review for journal Biogeosciences

Discussion started: 13 November 2017

(c) Author(s) 2017. CC BY 4.0 License.

release (24 and references therein). However, they primarily have more short-term influence on sporulation and atmospheric residence, which may be masked by the grouping into months.

Again, distinct differences are seen between the lifestyle groups. The herbaceous-plant-associated fungi show the strongest correlations. Temperature especially displays strong positive and negative correlations. Temperature is well known to be a

5 main factor in germination hyphal growth and sporulation (Ayerst, 1969; Tommerup, 1983) which also makes sense for fungi with seasonal dispersal strategies, aimed at different stages in the vegetative cycle of plants. The woody-plant associated on the other hand show fewer sporadic correlations. Most of the more significant correlations are observed with wind speed, which may reflect the need for higher wind speeds for liberation from the sheltered forest floor or canopy.

The aerodynamic properties of spores are also an important property that can also influence the inoculation probability as they

10 are a determining factor in the potential atmospheric residence time and spore-deposition. In Figure 4 we show the calculated aerodynamic diameter for each taxon in the 5-sample-subset against the ratio of the coarse to fine particle fraction occurrences, i.e., in the size fractions above and below the theoretical sampler cut-off of $3 \mu \mathrm{m}$ aerodynamic diameter. When viewing the figure, it should be noted that the calculated aerodynamic diameters are rough estimations as they only account for spore physical size and shape described in literature. Factors such as spore density, inhomogeneous density distribution and spore surface composition, will also affect a spore's aerodynamic properties. However, due to lack of information in literature on factors apart from shape and dimensions, a uniform density of $1 \mathrm{~g} \mathrm{~cm}^{-3}$ was applied to all taxa. The few examples of densities mentioned by Gregory (Gregory, 1961) range between $0.56-1.44 \mathrm{~g} \mathrm{~cm}^{-3}$, which would translate to a reduction or increase of the aerodynamic diameters by $\sim 25 \%$ or $\sim 20 \%$, respectively. He also mentions that spores typically are slightly denser than water, in the range of 1.1-1.2 $\mathrm{g} \mathrm{cm}^{-2}$. Reponen et al. (Reponen et al., 2001) compared the physical and aerodynamic size of

20 spores and found a large variation between different species and also a dependency on the hydration level of the measured spores. Despite these uncertainties, an obvious increase in calculated diameters can be observed in Figure 4 over the range from fine to coarse. This is also a strong indication that we are in fact predominantly observing spores rather than hyphal fragments, which potentially also can be aerosolized. Sporobolomyces coprosmae seems to contradict the increasing trend, overweighing in the coarse fraction despite having relatively small spores. It is, however, a yeast-like single celled fungus.

25 This makes it feasible that the larger vegetative cells (calculated aerodynamic diameter: $3.5-5.3 \mu \mathrm{m}$ ) are predominantly being sampled.

When considering the lifestyle classifications, three groups can be identified, indicated by the shaded ellipses I-III. All of the woody-plant-associated taxa, with exception of Vuilleminia comedens, lie within the central group III that are more or less evenly distributed between the size fractions. The herbaceous-plant-associated fungi on the other hand display two distinct

30 groups: (A) group I containing taxa predominant in the fine fraction to taxa evenly distributed between the size fractions and (B) cluster II with taxa dominating in the coarse particle fraction. Group I exclusively contains the cosmopolitan mold fungi genera Cladosporium, Penicillium and Aspergillus, while Group II contains all plant pathogens and plant surface inhabiting fungi. 
Biogeosciences Discuss., https://doi.org/10.5194/bg-2017-452

Manuscript under review for journal Biogeosciences

Discussion started: 13 November 2017

(c) Author(s) 2017. CC BY 4.0 License.

The three groups could again reflect different distinct dispersal strategies dependent on the primary environment and substrates of the taxa. In general, a large aerodynamic diameter of a spore and therefore a relatively high inertia has the benefit of being able to overcome the laminar airflow close to an object's surface and have a higher impaction probability compared to small spores that will tend to follow the airflow around a plant's surface. This is reflected by the taxa within Group II, all of which

5 are plant pathogens (or in the case of the genera have species known to be pathogenic), live on plant surfaces or in the case of Vuilleminia comedens known to inoculate dying still attached branches (Boddy and Thompson, 1983).

Group I is exclusively made up by the cosmopolitan mold fungi (Cladosporium, Penicillium and Aspergillus) which are either evenly distributed between the fractions or overweigh in the fine fraction, i.e., display an aerodynamic diameter around or lower than the sampler cut-off. Many species belonging to these genera are known to be unspecific when it comes to substrates

10 and they are found in many different environments. The unspecific nature of the genera may be reflected in the small spore sizes. In other words, the mold fungi can produce large quantities of small conidia and can rely on sedimentation (e.g., on plant litter) for a successful inoculation. Furthermore, the asexual conidia are produced in chains. Dependent on conditions and the species, the mold fungi conidia are known to be liberated in mixture of single spores and multi-spore chains (Gregory, 1961). This leads to a broader aerodynamic size range and thereby does not rule out impaction inoculation. This may also be a factor

15 playing a role in the even distribution of Cladosporium sp. and Aspergillus sp.(A) between the fractions.

The wood fungi cluster in Group III and therefore display aerodynamic diameters around the sampler cut off. The fungi being adapted to a forest environment can most feasibly explain this. A forest canopy will act as a wind shield resulting in reduced wind speeds and turbulence. A small aerodynamic diameter will aid the spore spread in calm conditions due to the slower settling velocities and therefore longer atmospheric residence times. In addition, dead wood is not as ubiquitous as, e.g.,

20 decaying plant litter making a sufficient spread key to a successful inoculation. Furthermore, many tree pathogens, such as Heterobasidion annosum, can only infect wounded hosts or alternately must inoculate a tree stump and then further spread across the root systems. Damaged hosts and tree stumps under normal conditions will be relatively scarce, which would make a large spread of a large number of spores essential.

In summary we were able to identify lifestyle-dependent patterns temporal and size fraction occurrences which to large part would have remained hidden by solely viewing the dataset from a taxonomic perspective. This approach opens up new possibilities for the analysis of the atmospheric microbiome. For instance, a similar classification scheme could be used as a simplification for larger scale atmospheric and forecast modelling of bioaerosol emissions, making the source habitat emission estimates over time of parameters like number concentrations and physical characteristics of the different spore types a far less daunting task. We also presented evidence for a significant shift in early year sporulation due to the unusually warm winter of

30 2006/2007. This should be of concern for diverse fields, such as food security, agriculture and human health, which will be central challenges for the Anthropocene. Further systematic studies are needed to assess and prepare for potentially farreaching effects of climate change on the atmospheric microbiome. 
Biogeosciences Discuss., https://doi.org/10.5194/bg-2017-452

Manuscript under review for journal Biogeosciences

Discussion started: 13 November 2017

(c) Author(s) 2017. CC BY 4.0 License.

\section{Data availability}

The underlying data used in this study can be found in Fröhlich-Nowoisky et al., 2009, and corresponding supplementary material. The OTU reference sequences used in this study can be found in the NCBI nucleotide database (www.ncbi.nlm.nih.gov) under the accession numbers: FJ820489-FJ820856.

\section{Competing interests}

The authors declare that they have no conflict of interest

\section{Acknowledgements}

We thank J. Cimbal, I. Müller-Germann, David Teschner and Sebastian Brill for technical assistance; M. O. Andreae, W. Elbert, H. Paulsen, D. Begerow, S. Benner, A. T. Kunert and colleagues from the Mainz Bioaerosol Laboratory (MBAL) for helpful discussions and support; U. Kampe for providing air quality data; and we thank the Max Planck-Genome-centre Cologne (http://mpgc.mpipz.mpg.de/home/) for performing DNA sequencing in this study. This work was supported by the Max Planck Society.

\section{References}

Ayerst, G.: The effects of moisture and temperature on growth and spore germination in some fungi, J. Stored Prod. Res., 5, 15 127-141, doi:10.1016/0022-474X(69)90055-1, 1969.

Boddy, L. and Thompson, W.: Decomposition of Suppressed Oak Trees in Even-Aged Plantations. I. Stand Characteristics and Decay of Aerial Parts, New Phytol., 93(2), 261-276, doi:10.1111/j.1469-8137.1983.tb03430.x, 1983.

Boddy, L., Büntgen, U., Egli, S., Gange, A. C., Heegaard, E., Kirk, P. M., Mohammad, A. and Kauserud, H.: Climate variation effects on fungal fruiting, Fungal Ecol., 10(1), 20-33, doi:10.1016/j.funeco.2013.10.006, 2014.

20 Bowers, R. M., McCubbin, I. B., Hallar, A. G. and Fierer, N.: Seasonal variability in airborne bacterial communities at a highelevation site, Atmos. Environ., 50, 41-49, doi:10.1016/j.atmosenv.2012.01.005, 2012.

Bowers, R. M., Clements, N., Emerson, J. B., Wiedinmyer, C., Hannigan, M. P. and Fierer, N.: Seasonal variability in bacterial and fungal diversity of the near-surface atmosphere, Environ. Sci. Technol., 47(21), 12097-12106, doi:10.1021/es402970s, 2013.

25 Cao, C., Jiang, W., Wang, B., Fang, J., Lang, J., Tian, G., Jiang, J. and Zhu, T. F.: Inhalable Microorganisms in Beijing's PM 2.5 and PM 10 Pollutants during a Severe Smog Event, Environ. Sci. Technol., 48(3), 1499-1507, doi:10.1021/es4048472, 2014.

Davis, E. J. and Schweiger, G.: The Airborne Microparticle: Its Physics, Chemistry, Optics, and Transport Phenomena, Springer Berlin Heidelberg., 2002.

30 Deacon, J. W.: Fungal Biology, Wiley., 2013.

Després, V. R., Alex Huffman, J., Burrows, S. M., Hoose, C., Safatov, A. S., Buryak, G., Fröhlich-Nowoisky, J., Elbert, W., Andreae, M. O., Pöschl, U. and Jaenicke, R.: Primary biological aerosol particles in the atmosphere: a review, Tellus B, 64, 
Biogeosciences Discuss., https://doi.org/10.5194/bg-2017-452

Manuscript under review for journal Biogeosciences

Discussion started: 13 November 2017

(c) Author(s) 2017. CC BY 4.0 License.

doi:10.3402/tellusb.v64i0.15598, 2012.

Donnelly, D. P. and Boddy, L.: Development of mycelial systems of Stropharia caerulea and Phanaerochaete velutina on soil: effect of temperature and water potential, Mycol. Res., 101(May), 705-713, doi:10.1017/S0953756296003280, 1997.

Dowson, C., L, B. and ADM, R.: Development and extension of myceiial cords in soil at different temperatures and moisture contents, Mycol. Res., 92(4), 383-391, doi:10.1016/S0953-7562(89)80181-9, 1989.

Elbert, W., Taylor, P. E., Andreae, M. O. and Pöschl, U.: Contribution of fungi to primary biogenic aerosols in the atmosphere: wet and dry discharged spores, carbohydrates, and inorganic ions, Atmos. Chem. Phys., 7(17), 4569-4588, doi:10.5194/acp7-4569-2007, 2007.

Franzetti, A., Gandolfi, I., Gaspari, E., Ambrosini, R. and Bestetti, G.: Seasonal variability of bacteria in fine and coarse urban air particulate matter., Appl. Microbiol. Biotechnol., 90(2), 745-53, doi:10.1007/s00253-010-3048-7, 2011.

Fröhlich-Nowoisky, J., Pickersgill, D. A., Després, V. R. and Pöschl, U.: High diversity of fungi in air particulate matter., Proc. Natl. Acad. Sci. U. S. A., 106(31), 12814-12819, doi:10.1073/pnas.0811003106, 2009.

Fröhlich-Nowoisky, J., Burrows, S. M., Xie, Z., Engling, G., Solomon, P. a., Fraser, M. P., Mayol-Bracero, O. L., Artaxo, P., Begerow, D., Conrad, R., Andreae, M. O., Després, V. R. and Pöschl, U.: Biogeography in the air: fungal diversity over land and oceans, Biogeosciences, 9(3), 1125-1136, doi:10.5194/bg-9-1125-2012, 2012.

Fröhlich-Nowoisky, J., Ruzene Nespoli, C., Pickersgill, D. A., Galand, P. E., Müller-Germann, I., Nunes, T., Gomes Cardoso, J., Almeida, S. M., Pio, C., Andreae, M. O., Conrad, R., Pöschl, U. and Després, V. R.: Diversity and seasonal dynamics of airborne archaea, Biogeosciences, 11(21), 6067-6079, doi:10.5194/bg-11-6067-2014, 2014.

Fröhlich-Nowoisky, J., Hill, T. C. J., Pummer, B. G., Yordanova, P., Franc, G. D. and Pöschl, U.: Ice nucleation activity in the widespread soil fungus Mortierella alpina, Biogeosciences, 12(4), 1057-1071, doi:10.5194/bg-12-1057-2015, 2015.

Fröhlich-Nowoisky, J., Kampf, C. J., Weber, B., Huffman, J. A., Pöhlker, C., Andreae, M. O., Lang-Yona, N., Burrows, S. M., Gunthe, S. S., Elbert, W., Su, H., Hoor, P., Thines, E., Hoffmann, T., Després, V. R. and Pöschl, U.: Bioaerosols in the Earth System: Climate, Health, and Ecosystem Interactions, Atmos. Res., doi:10.1016/j.atmosres.2016.07.018, 2016.

Gange, A. C., Gange, E. G., Sparks, T. H. and Boddy, L.: Rapid and Recent Changes in Fungal Fruiting Patterns, Science (80-

Gregory, P. H.: The microbiology of the atmosphere., London,L. Hill;, 1961.

Horner, W. E., Helbling, A., Salvaggio, J. E. and Lehrer, S. B.: Fungal Allergens, Clin. Microbiol. Rev., 8(2), 161-179, 1995.

Huffman, J. A., Treutlein, B. and Pöschl, U.: Fluorescent biological aerosol particle concentrations and size distributions measured with an Ultraviolet Aerodynamic Particle Sizer (UV-APS) in Central Europe, Atmos. Chem. Phys., 10(7), 321530 3233, doi:10.5194/acp-10-3215-2010, 2010.

Jones, A. M. and Harrison, R. M.: The effects of meteorological factors on atmospheric bioaerosol concentrations--a review., Sci. Total Environ., 326(1-3), 151-80, doi:10.1016/j.scitotenv.2003.11.021, 2004.

Kuo, M.: Bjerkandera adusta, [online] Available from: http://www.mushroomexpert.com/bjerkandera_adusta.html, 2010.

van Laarhoven, K. A., Huinink, H. P., Segers, F. J. J., Dijksterhuis, J. and Adan, O. C. G.: Separate effects of moisture content 35 and water activity on the hyphal extension of Penicillium rubens on porous media, Environ. Microbiol., 17(12), 5089-5099, doi:10.1111/1462-2920.13012, 2015.

O’Brien, H. E., Parrent, J. L. J. L., Jackson, J. a. J. a, Moncalvo, J. J. M. J., Vilgalys, R. and Brien, H. E. O.: Fungal community analysis by large-scale sequencing of environmental samples, Appl. Environ. Microbiol., 71(9), 5544-5550, doi:10.1128/AEM.71.9.5544, 2005. 
Biogeosciences Discuss., https://doi.org/10.5194/bg-2017-452

Manuscript under review for journal Biogeosciences

Discussion started: 13 November 2017

(c) Author(s) 2017. CC BY 4.0 License.

Ostry, M. E. and Juzwik, J.: Selected Forest and Shade Tree Disease of Significance in the 20th Century, APSnet Featur., doi:10.1094/APSnetFeatures-2008-0508, 2008.

Pady, S. M. and Gregory, P. H.: Numbers and viability of airborne hyphal fragments in England, Trans. Br. Mycol. Soc., 46(4), 609-613, doi:10.1016/S0007-1536(63)80063-7, 1963.

5 Pöschl, U.: Atmospheric aerosols: composition, transformation, climate and health effects., Angew. Chem. Int. Ed. Engl., 44(46), 7520-40, doi:10.1002/anie.200501122, 2005.

Reponen, T., Grinshpun, S. a., Conwell, K. L., Wiest, J. and Anderson, M.: Aerodynamic versus physical size of spores: Measurement and implication for respiratory deposition, Grana, 40(3), 119-125, doi:10.1080/00173130152625851, 2001.

Richard, C., Martin, J. G. and Pouleur, S.: Ice nucleation activity identified in some phytopathogenic Fusarium species, Phytoprotection, 77(2), 83-92, doi:10.7202/706104ar, 1996.

Roskov, Y., Abucay, L., Orrell, T., Nicolson, D., Kunze, T., Culham, A., Bailly, N., Kirk, P., Bourgoin, T., DeWalt, R. E., Decock, W., De Wever, A. and Eds.: Species 2000 \& ITIS Catalogue of Life, 2015 Annual Checklist, Species 2000 Nat. Leiden, Netherlands [online] Available from: www.catalogueoflife.org/annual-checklist/2015, 2015.

Solomon, P. A., Moyers, J. L. and Fletcher, R. A.: High-Volume Dichotomous Virtual Impactor for the Fractionation and

15 Collection of Particles According to Aerodynamic Size, Aerosol Sci. Technol., 2(4), 455-464, doi:10.1080/02786828308958649, 1983.

Stenlid, J., Karlsson, M., Lind, M., Lunden, K., Adomas, A., Asiegbu, F. and Olson, Åk.: Pathogenicity in Heterobasidion annosum s.1., Aktuelt fra skogsforskningen, 13-15, 2000.

Strange, R. N. and Scott, P. R.: Plant disease: a threat to global food security., Annu. Rev. Phytopathol., 43, 83-116, doi:10.1146/annurev.phyto.43.113004.133839, 2005.

Taylor, J., Jacobson, D. and Fisher, M.: The Evolution of Asexual Fungi: Reproduction, specification and classification, Annu. Rev. Phytopathol., 37, 197-246, 1999.

Tommerup, I. C.: Temperature relations of spore germination and hyphal growth of vesicular-arbuscular mycorrhizal fungi in soil, Trans. Br. Mycol. Soc., 81(2), 381-387, doi:10.1016/S0007-1536(83)80090-4, 1983.

25 Tsitsigiannis, D. I., Kowieski, T. M., Zarnowski, R. and Keller, N. P.: Endogenous lipogenic regulators of spore balance in Aspergillus nidulans., Eukaryot. Cell, 3(6), 1398-1411, doi:10.1128/EC.3.6.1398, 2004.

Wang, C.-C., Fang, G.-C. and Lee, L.-Y.: The Study of Ambient Air Bioaerosols During Summer Daytime and Nighttime Periods in Taichung, Central Taiwan, Environ. Forensics, 9(1), 6-14, doi:10.1080/15275920701729175, 2008.

Wolf, J., O’Neill, N. R., Rogers, C. A., Muilenberg, M. L. and Ziska, L. H.: Elevated atmospheric carbon dioxide

30 concentrations amplify Alternaria alternate sporulation and total antigen production, Environ. Health Perspect., 118(9), 12231228, doi:10.1289/ehp.0901867, 2010.

Yamamoto, N., Bibby, K., Qian, J., Hospodsky, D., Rismani-Yazdi, H., Nazaroff, W. W. and Peccia, J.: Particle-size distributions and seasonal diversity of allergenic and pathogenic fungi in outdoor air, ISME J., 6(10), 1801-1811, doi:10.1038/ismej.2012.30, 2012.

35 Yooseph, S., Andrews-Pfannkoch, C., Tenney, A., McQuaid, J., Williamson, S., Thiagarajan, M., Brami, D., Zeigler-Allen, L., Hoffman, J., Goll, J. B., Fadrosh, D., Glass, J., Adams, M. D., Friedman, R. and Venter, J. C.: A metagenomic framework for the study of airborne microbial communities, PLoS One, 8(12), doi:10.1371/journal.pone.0081862, 2013.

Zabel, R. A. and Morrell, J. J.: Wood Microbiology: Decay and Its Prevention, Elsevier Science., 2012. 
Figures

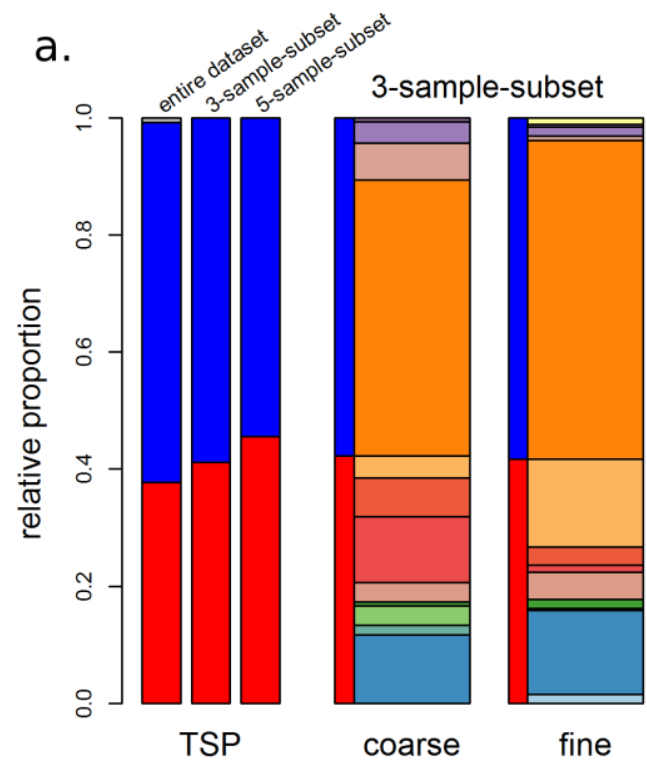

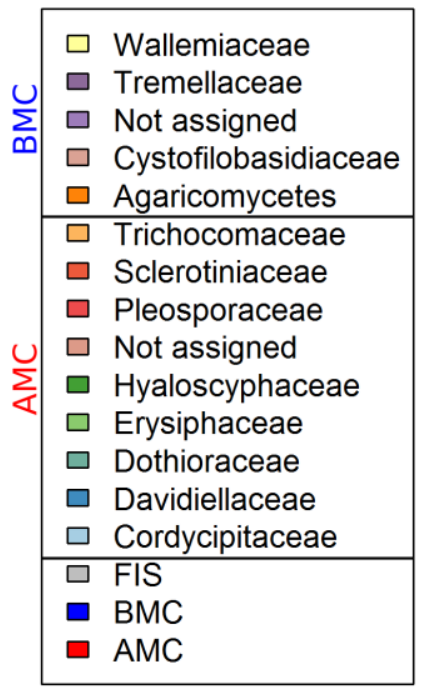

b.
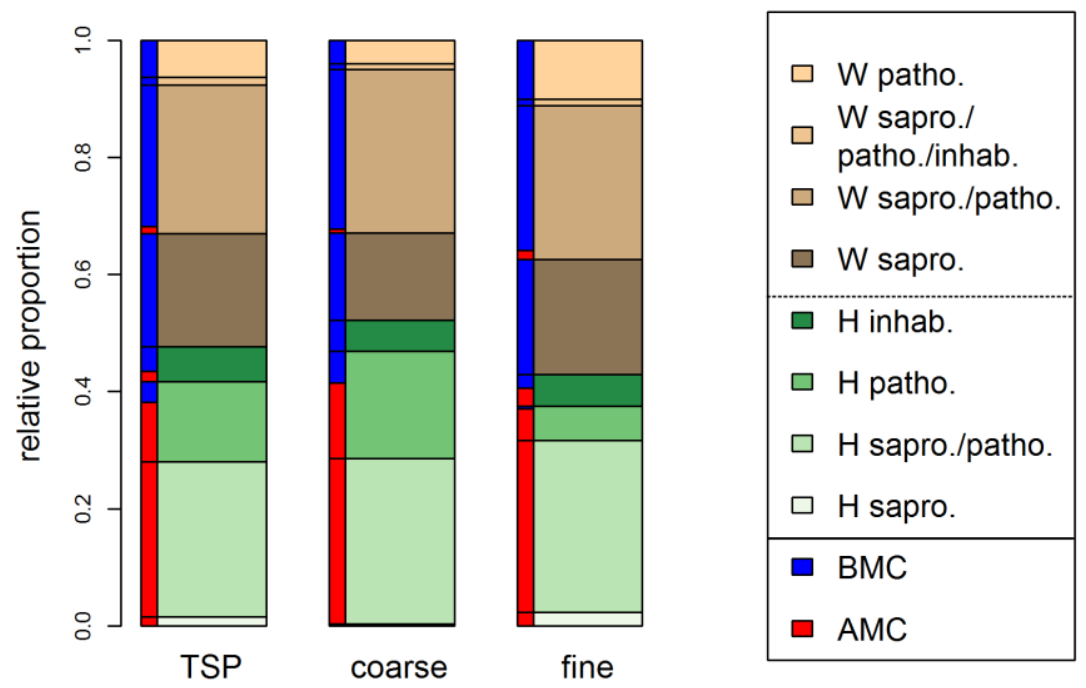

Figure 1: Occurrence-weighted taxonomic and lifestyle composition in total suspended particles (TSP) and the coarse and fine particle fractions. a.: Taxonomic composition. The TSP show the relative proportions on phylum level for the entire dataset, the 3-sample-subset and the 5-sample-subset. Coarse and fine show the relative proportions on family and phylum level (thin side bars) for the coarse and fine particle fraction of the 3-sample-subset. For reasons of clarity all families belonging to the class of Agaricomycetes have not been resolved. AMC: Ascomycota, BMC: Basidiomycota, FIS: Fungi Incertae Sedis. b.: Lifestyle classification distribution of the 3-sample-subset along with the corresponding phylum distribution of the individual groups (thin side bars). H: herbaceous-plant-associated, W: woody plant associated, sapro.: saprophytic, patho.: pathogenic, inhab.: surface inhabiting. 
Biogeosciences Discuss., https://doi.org/10.5194/bg-2017-452

Manuscript under review for journal Biogeosciences

Discussion started: 13 November 2017

(c) Author(s) 2017. CC BY 4.0 License.

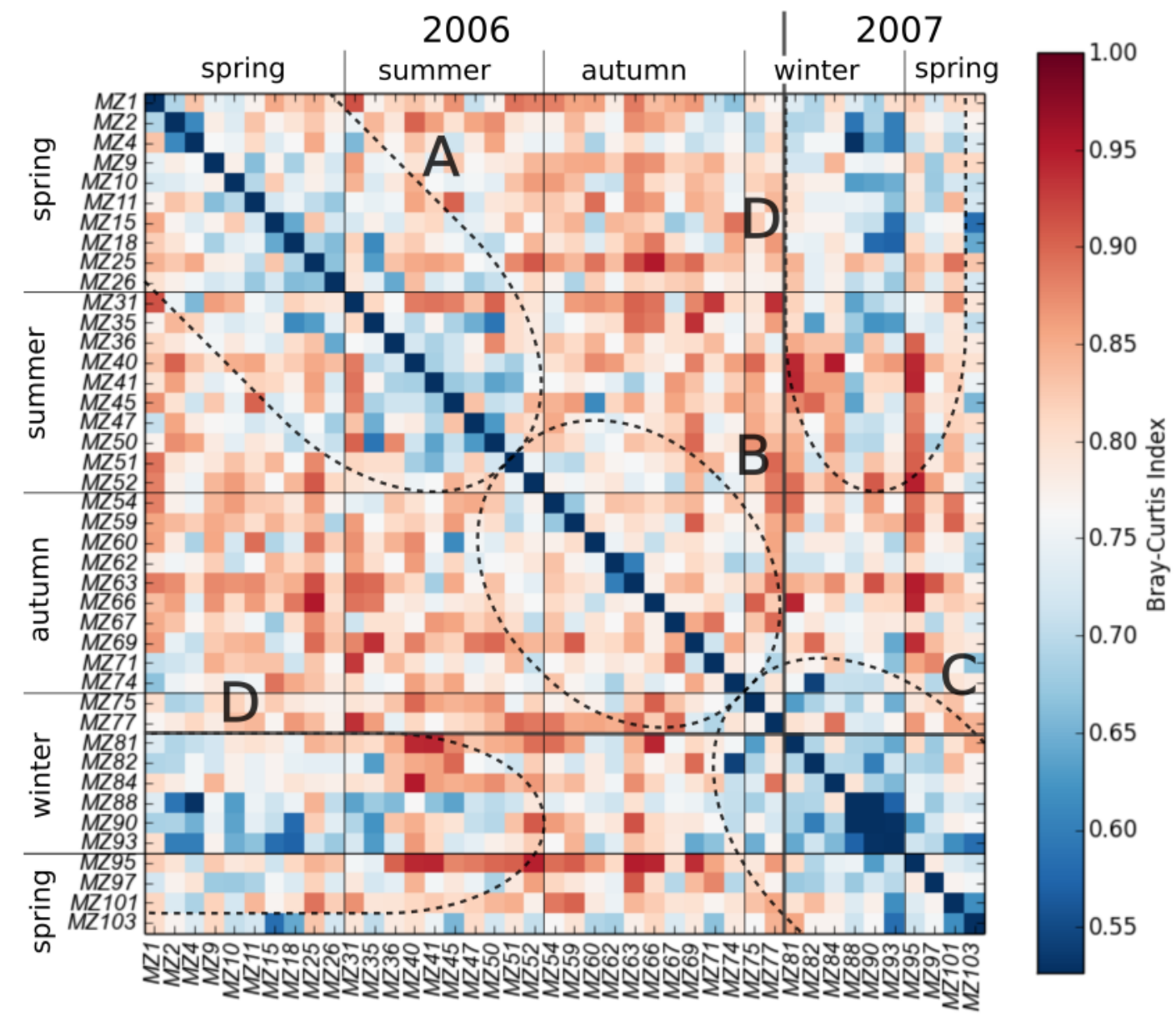

Figure 2: Inter-sample variability of OTU composition ( $\beta$-diversity) for the entire dataset (TSP) using the Bray-Curtis Dissimilarity index. The consecutively numbered sample IDs of the sampling campaign are shown, which were also grouped into meteorological seasons. The Bray Curtis Index is the ratio of OTUs that differ between two samples, ranging from 1 being a completely different OTU composition to 0 being an identical composition. Note that the used color scale ranges from 1 to 0.52 , as this was the lowest index calculated between two samples. A-D: Areas of interest referenced within the text. 
Biogeosciences Discuss., https://doi.org/10.5194/bg-2017-452

Manuscript under review for journal Biogeosciences

Discussion started: 13 November 2017

(c) Author(s) 2017. CC BY 4.0 License.

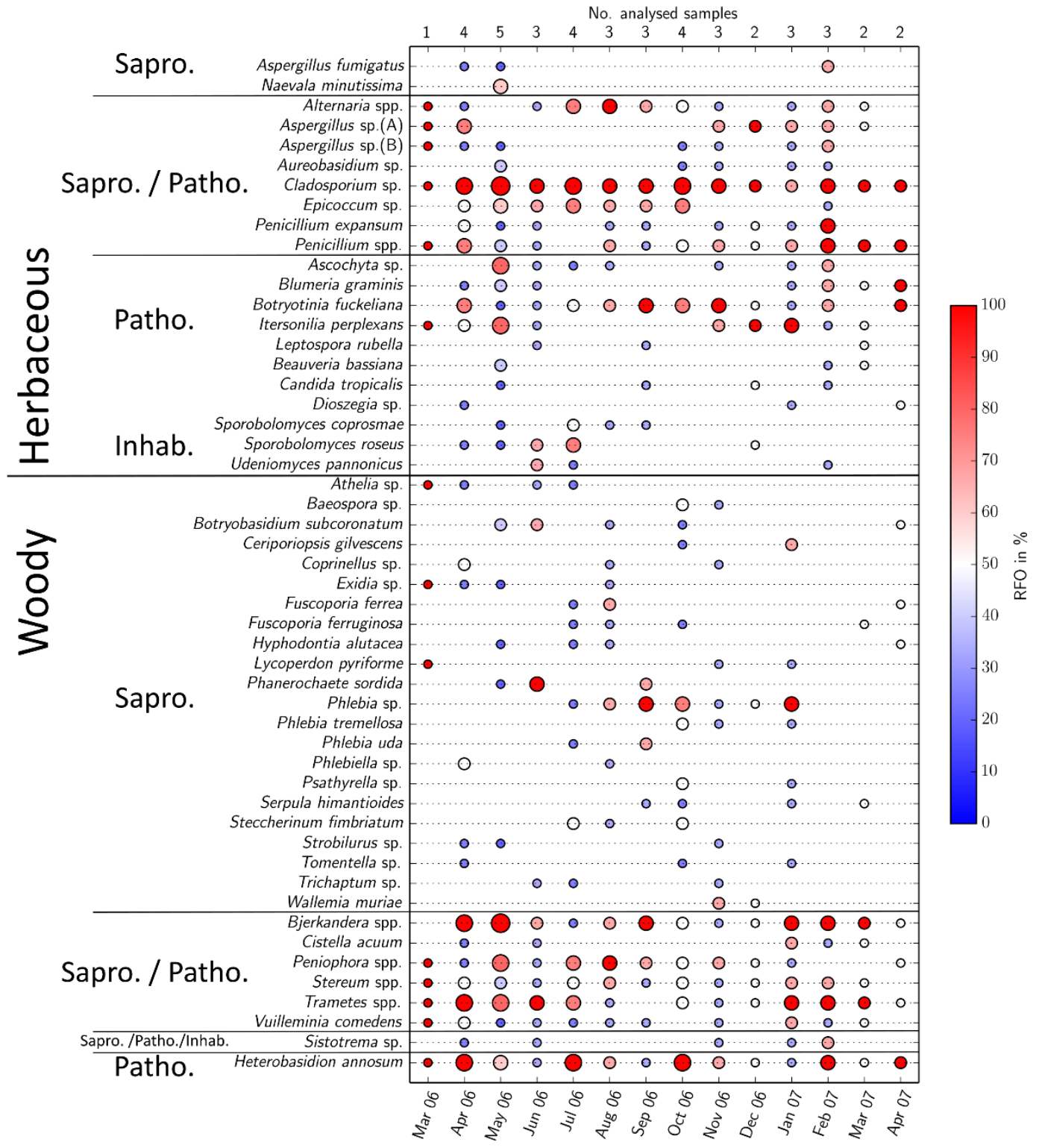

Figure 3: Temporal dynamics of the relative abundance of the taxa in the 3-sample-subset ordered according to the allocated lifestyle classification. The colors of the points correspond to the relative frequency of occurrence (RFO) for each species or genus and in a given month. The point sizes scale, both with the RFO-value and the number of analyzed samples for each month to additionally weight months with a higher number of analyzed samples (point size $=$ RFO *no. analyzed samples/3). 
Biogeosciences Discuss., https://doi.org/10.5194/bg-2017-452

Manuscript under review for journal Biogeosciences

Discussion started: 13 November 2017

(c) Author(s) 2017. CC BY 4.0 License.

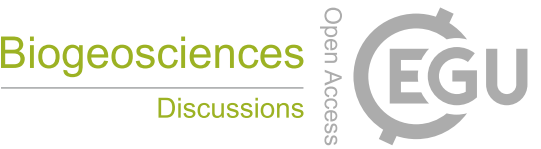

(c) (i)

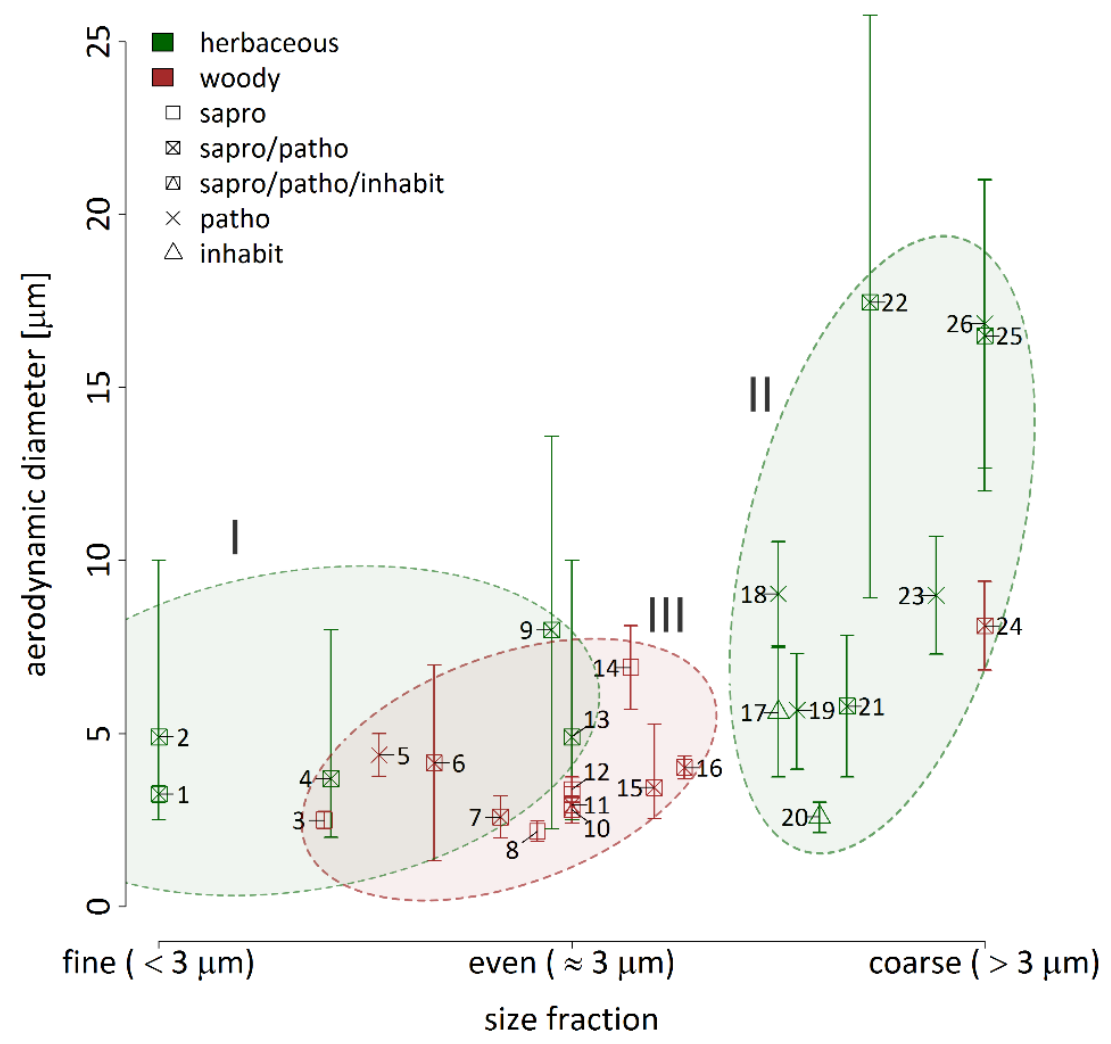

1: Penicillium expansum

2: Aspergillus sp.(B)

3: Steccherinum fimbriatum

4: Penicillium spp.

5: Heterobasidion annosum

6: Cistella acuum

7: Trametes spp.

8: Phlebia sp.

9: Cladosporium sp.

10: Sistotrema sp.

11: Bjerkandera spp.

12: Phanerochaete sordida

13: Aspergillus sp.(A)

14: Botryobasidium subcoronatum

15: Stereum spp.

16: Peniophora spp.

17: Sporobolomyces roseus

18: Botryotinia fuckeliana

19: Ascochyta sp.

20: Sporobolomyces coprosmae

21: Aureobasidium sp.

22: Alternaria spp.

23: Itersonilia perplexans

24: Vuilleminia comedens

25: Epicoccum sp.

26: Blumeria graminis

Figure 4: The estimated aerodynamic diameter against the size distribution for taxa found in the 5-sample-subset. The estimated aerodynamic diameter was calculated using spore dimensions found in literature (see supplementary table S2). The size distribution was calculated by subtracting the number of occurrences in the fine fraction from the occurrences in the coarse fraction and dividing the difference by the TSP occurrences. This shows which size fraction and to what extent the taxa were predominately found in. The color and point types correspond to the lifestyle categorization displayed in the legend. The shaded ellipses represent three identified clusters. I: hypothesized sedimentation adapted spores; II: hypothesized impaction adapted spores; III: hypothesized forest adapted spores. 